\title{
Increasing Performance and Thermostability of D-Phenylglycine Aminotransferase in Miscible Organic Solvents
}

\author{
Hossein Javid ${ }^{1,2 *}$, Suthep Wiyakrutta ${ }^{2}$ \\ ${ }^{1}$ Department of Reproductive Genetics, Royan Reproductive Biomedicine Research Center, ACECR, Tehran, Iran \\ ${ }^{2}$ Department of Microbiology, Faculty of Science, Mahidol University, Rama VI Rd., Ratchathewi, Bangkok 10400, Thailand \\ "Corresponding author: Hossein Javid, Department of Reproductive Genetics, Royan Reproductive Biomedicine Research Center, ACECR, Tehran, Iran \\ E-mail: h.javid@royaninstitute.org, Tel: +98-2123562628, Fax:+98-2127635509
}

Received: 16 Jan. 2018; $\quad$ Revised: 8 Aug. 2018; $\quad$ Accepted: 11 Aug. 2018; $\quad$ Published online: 11 Dec. 2018

\begin{abstract}
Background: D-Phenylglycine aminotransferase (D-PhgAT) is highly beneficial in pharmaceutical biotechnology. Like many other enzymes, D-PhgAT suffers from low stability under harsh processing conditions, poor solubility of substrate, products and occasional microbial contamination. Incorporation of miscible organic solvents into the enzyme's reaction is considered as a solution for these problems; however, native D-PhgAT is not significantly stable in such solvents.

Objective: Halophiles are known to survive and withstand unsavory habitats owing to their proteome bios. In the current study, with an eye on further industrial applications, we examined the performance and thermostability of four halophilic peptides fused D-PhgAT variants in reaction mixtures of various proportions of different miscible organic solvents and various temperatures as well as desiccation.

Materials and Methods: Plasmid constructs from the previous study (Two alpha helixes and loops between them from Halobacterium salinarum ferredoxin enzyme fused at N-terminus domain of D-PhgAT) expressed in Escherichia coli and then D-PhgAT purified. Purified proteins were subjected to various proportions of miscible organic solvents, different temperatures, and desiccation and then performance and thermostability monitored.

Results: Study confirmed increased $C_{50}$ of all halophilic fused D-PhgAT variants, where the highest $C_{50}$ observed for ALALD-PhgAT $(30.20 \pm 2.84 \% \mathrm{~V} / \mathrm{V})$. Additionally, all halophilic fused variants showed higher thermostability than the wild-type D-PhgAT in the presence of different fractions of acetone, $N, N$-Dimethylformamide and isopropanol in aqueous binary media, while zero activity observed at the presence of methanol.

Conclusion: Our results suggest that applying this new technique could be invaluable for making enzymes durable in discordant industrial conditions.

Keywords: D-Phenylglycine aminotransferase; Halophilic peptide fusion; Miscible organic solvents; Stability
\end{abstract}

\section{Background}

Stereo-inverting pyridoxal-5'-phosphate dependent D-Phenylglycine aminotransferase (D-PhgAT; EC 2.6.1.72) is highly beneficial for pharmaceutical and biotechnological utilizations e.g., production of enantiomerically pure synthons and side chain moieties such as $\mathrm{D}-(-)-\alpha-$ Phenylglycine and 4 -Hydroxy-Dphenylglycine, which are essential for manufacturing highly demanded semi-synthetic antibiotics from cheap L-Glutamate and benzoylformate as substrates
$(1,2)$.

The biggest obstacle in using enzymes is their low stability under detrimental processing conditions (3) and occasional microbial contaminations (4); which D-PhgAT is not exceptional. Incorporating miscible organic solvents into reaction or storage buffers considered as a prominent solution for these major problems. Additionally, owing to shift the thermodynamic equilibrium, incorporating miscible organic solvents into media prevents unfavorable aqua-

Copyright (C) 2018 The Author(s); Published by National Institute of Genetic Engineering and Biotechnology. This is an open access article, distributed under the terms of the Creative Commons Attribution-NonCommercial 4.0 International License (http://creativecommons.org/licenses/ by-nc/4.0/) which permits others to copy and redistribute material just in noncommercial usages, provided the original work is properly cited. 
induced reactions (5). Moreover, organic solvents, provide media for solubilization of substrates (6) or products, where poorly soluble or even insoluble components are desired. Despite these invaluable benefits, yet many enzymes might be inactive in organic solvents (7). Various techniques have been investigated to prevail and minimize instability impediments e.g., screening intrinsically stabilized extremozymes (8), enzymes production in genetically modified organisms (9), modification of amino acid signature in mesophilic enzymes (10) and chemical modification of enzymes $(11,12)$.

Extremozymes from extremophiles are stable and functionally active under precluding conditions where other proteins cannot withstand (13). Among these extremophiles, halophiles are considered as tenacious microorganisms in hypersaline habitats and as natural sources for halophilic enzymes (14). Recovery of 41 million-year-old halophilic bacteria (15) shows their survival capability in desiccation or very minute water in fluid inclusions. Adaptation to low water activity $\left(\mathrm{a}_{\mathrm{w}}\right)$ and high salt are the survival key in salty dry habitats. Since halophilic proteins are functional at low $\mathrm{a}_{\mathrm{w}}(16)$; they supposed to be stable and active in net organic solvents or in a water-organic binary solvent (17).

In our previous study (2), mesophilic D-PhgAT was successfully fused on its N-terminus domain with two highly negatively charged alpha helixes $\left(\mathrm{A}_{1}\right.$ and $\mathrm{A}_{2}$ ) and a hybrid of them connected with two loops (ALAL) from halophilic ferredoxin of Halobacterium salinarum (Hs Fdx; PDB: 1E0Z_A). The solubility and activity of these variants $\left(\mathrm{A}_{1}-\mathrm{D}-\mathrm{PhgAT}, \mathrm{A}_{2}-\mathrm{D}\right.$ PhgAT and ALAL-D-PhgAT) determined in various concentrations of L-glutamate sodium salt as substrate and other additives to the reaction mixture. Results showed the solubility and performance of the ALALD-PhgAT variant increased significantly compared with wild-type and other two variants.

In the current study, for the first time, we determine the performance and thermostability of D-PhgAT variants in presence of different fractions of watermiscible organic binary solvents.

\section{Objective}

Since halophiles are capable to survive their unsavory habitats owning to their proteome bios and with an eye on further industrial applications of D-PhgAT, we investigate the performance and thermostability of halophilic peptide fused D-PhgAT in presence of different proportions of miscible organic solvents, temperature and desiccation.

\section{Materials and Methods}

\subsection{Expression and Purification of D-PhgAT}

Construction of plasmids and expression of different D-PhgAT variants are explained in (2). Briefly, oligonucleotides of two alpha helixes $\left(\mathrm{A}_{1}\right.$ and $\left.\mathrm{A}_{2}\right)$ and two loops (ALAL) synthesized base on amino acid sequences of $H s \mathrm{Fdx}$. These Oligonucleotides ligased to $\mathrm{pET}-17 \mathrm{~b}$ possessing $d p g A$ gene for coding D-PhgAT. The construct was transfected to Escherichia coli XL-10 Gold and checked by colony PCR and Sanger sequencing. D-PhgAT expression performed in E. coli tuner (DE3) pLysS at $0.4 \mathrm{mM}$ IPTG. After $16 \mathrm{~h}$ expression at $20^{\circ} \mathrm{C}$ and $100 \mathrm{rpm}$, cells were harvested at $13,000 \times \mathrm{g}, 4^{\circ} \mathrm{C}$ for 40 min by Sorvall ${ }^{\circledR}$ RC 5C Plus centrifuge (Kendro Laboratory Products, USA) and resuspended in lysis buffer (20 mM Tris-HCl pH 7.6, $1 \mathrm{mM}$ EDTA, 0.01\% $\beta$-mercaptoethanol and $100 \mu \mathrm{M}$ pyridoxal phosphate). Ultra-sonic cell disruption performed on ice in 20 cycles of $10 \mathrm{~s}$ burst and $10 \mathrm{~s}$ cooling intervals by Vibra-Cell ${ }^{\mathrm{TM}}$ SONICS (Sonics and Materials INC., USA), followed by centrifugation at $17,000 \times \mathrm{g}, 4{ }^{\circ} \mathrm{C}$ and $20 \mathrm{~min}$ and followed by fractional ammonium sulfate precipitation. Protein pellet at $25-45 \%$ saturation which contained D-PhgAT (verified by SDS-PAGE and activity assay) was dissolved in TEMP buffer $(20 \mathrm{mM}$ Tris- $\mathrm{HCl} \mathrm{pH}$ 7.6, $1 \mathrm{mM}$ EDTA, 0.01\% $\beta$-mercaptoethanol and 2.5 $\mu \mathrm{M}$ pyridoxal phosphate) containing $1 \mathrm{M}$ ammonium sulfate. Protein mixture applied onto Phenyl Sepharose ${ }^{\circledR}$ FF Hydrophobic Interaction Chromatography (HIC) column (GE Healthcare Bio-Science, Uppsala, Sweden) pre-equilibrated with the same buffer. The elution of bound proteins achieved by a four-bed volume of linear descending gradient 1-0 $\mathrm{M}$ ammonium sulfate at 2 $\mathrm{mL} . \mathrm{min}^{-1}$ flow rate. Active fractions containing D-PhgAT then pooled, concentrated and desalted using Amicon ${ }^{\circledR}$ $30 \mathrm{kDa}$ cut off centrifugal device (Merck Millipore Ltd., Cork, Ireland) at $4,000 \times \mathrm{g}, 4{ }^{\circ} \mathrm{C}$ and $20 \mathrm{~min}$ and applied onto a DEAE Sepharose ${ }^{\mathrm{TM}}$ FF Ion Exchange Chromatography (IEX) column (GE Healthcare BioScience, Uppsala, Sweden) pre-equilibrated with TEMP buffer. The elution of bound proteins was achieved by an eight-bed volume of linear ascending $0-1 \mathrm{M} \mathrm{NaCl}$ in TEMP buffer. Active fractions containing D-PhgAT were pooled and desalted as mentioned above. ÄKTA purifier FPLC system (GE Healthcare Bio-Science, Uppsala, Sweden) used in all chromatography steps.

\subsection{D-PhgAT Assay}

D-PhgAT activity was assayed by monitoring the formation of benzoylformate upon transamination of D-(-)- $\alpha$-Phenylglycine with 2-oxoglutaric acid at 340 
$\mathrm{nm}$ for $180 \mathrm{~s}$. One milliliter of the reaction mixture contained: $20 \mu \mathrm{L}$ of enzyme solution, $10 \mathrm{mM}$ D-(-)$\alpha$-Phenylglycine, $10 \mathrm{mM}$ 2-oxoglutaric acid, $5 \mu \mathrm{M}$ pyridoxal phosphate, $5 \mu \mathrm{M}$ EDTA and $50 \mathrm{mM}$ CAPSO buffer $\mathrm{pH} 9.5$. The molar absorption of $24 \times 10^{3} \mathrm{M}^{-1} \mathrm{~cm}^{-1}$ was used to calculate the generated benzoylformate in $60 \mathrm{~s}$. One unit of D-PhgAT was defined as the amount of enzyme used for transamination of $1 \mu \mathrm{moL}$ of D(-)- $\alpha$-Phenylglycine to $1 \mu \mathrm{moL}$ benzoylformate per 60 s at $37^{\circ} \mathrm{C}$.

3.3. Effect of Different Miscible Organic Solvents on pH Values of D-PhgAT Reaction Buffer

Upon adding miscible organic solvent, the buffer $\mathrm{pH}$ may change (18), therefore determining the effect of organic solvents concentration on $\mathrm{pH}$ of D-PhgAT reaction buffer is critical. Modified method (19-21) used: $100 \mu \mathrm{L}$ of $500 \mathrm{mM}$ CAPSO buffer with various $\mathrm{pH}$ values, 40 $\mu \mathrm{L}$ of $\mathrm{pH}$ indicator solution $(0.85 \mathrm{mM}$ thymol blue and $10 \mathrm{mM} \mathrm{NaOH}$ ), and deionized sterile water mixed to the final concentration of $50 \mathrm{mM}$ CAPSO buffer. Helios Alpha UV-Vis spectrophotometer (Spectronic Unicam, Cambridge, UK) used to determine the absorption at $400 \mathrm{~nm}$ to $750 \mathrm{~nm}$ range and the maximum absorbance $\left(\lambda_{\max }\right)$. The equation (1) was used to calculate the pka of thymol blue $\mathrm{pH}$ indicator in different $\mathrm{pH}$ values:

$\log _{10}\left[\left(\mathrm{~A}-\mathrm{A}_{\text {Ind }}{ }^{-}\right) /\left(\mathrm{A}_{\mathrm{HInd}}-\mathrm{A}\right)\right]=\mathrm{pka}-\mathrm{pH}$

Where $\mathrm{A}_{\text {HInd }}$ and $\mathrm{A}_{\text {Ind }}-$ are $\lambda_{\max }$ of protonated and deprotonated forms of thymol blue in $50 \mathrm{mM}$ CAPSO buffer $\mathrm{pH} 2$ and 12, respectively at $594 \mathrm{~nm}$. Then 100 $\mu \mathrm{L}$ of $500 \mathrm{mM}$ CAPSO $\mathrm{pH} 9.5,40 \mu \mathrm{L}$ of $\mathrm{pH}$ indicator, different amounts of absolute miscible organic solvents (DMF, acetone, isopropanol and methanol) and deionized sterile water were mixed to the final concentration of 0 , $10,20,30$ and $40 \%$ of miscible organic solvents. Helios Alpha UV-Vis spectrophotometer used to determine the $\lambda_{\max }$ in presence of miscible organic solvents proportions. These $\lambda_{\max }$ values at $594 \mathrm{~nm}$ and pka from equation (1) used to calculate $\mathrm{pH}$ values of solutions containing miscible organic solvents concentrations. Then $\mathrm{pH}$ shift of CAPSO buffer $(\Delta \mathrm{pH})$ was obtained and used for the preparation of CAPSO buffer with various $\mathrm{pH}$ to minimize the $\mathrm{pH}$ shift upon adding solvents.

\subsection{D-PhgAT Assay in Various concentrations of Miscible Organic Solvents}

The reaction mixture $(1 \mathrm{~mL})$ contained $1 \mathrm{U}$ enzyme, $10 \mathrm{mM} \mathrm{D}-(-)-\alpha$-Phenylglycine, $10 \mathrm{mM}$ 2-oxoglutaric acid, $5 \mu \mathrm{M}$ pyridoxal phosphate, $5 \mu \mathrm{M}$ EDTA, $50 \mathrm{mM}$ CAPSO buffer with appropriate $\mathrm{pH}$ and $0,10,20,30$ and $40 \%$ of organic solvents. The concentration of organic solvents where $50 \%$ of activity remained $\left(C_{50}\right)$ was calculated for D-PhgAT variants.

\subsection{Effects of Absolute Organic Solvents, Desiccation} and Temperature on D-PhgAT Performance

One unit of enzyme variants in TEMP storage buffer vacuum centrifuged at $20{ }^{\circ} \mathrm{C}$ until completely dried. Then $10 \mu \mathrm{L}$ of deionized sterile water or $10 \mu \mathrm{L}$ of absolute organic solvents were added followed by incubation at 25,40 and $60{ }^{\circ} \mathrm{C}$ for $1 \mathrm{~h}$. Samples dried completely by vacuum centrifugation and $10 \mu \mathrm{L}$ of TEMP buffer was added for rehydration and then incubated on ice for $1 \mathrm{~h}$ followed by D-PhgAT activity assay.

\subsection{Statistical Analysis}

Experiments performed triplicated and analyzed by ANOVA. The $p<0.05$ considered as significant and used to construe data. Means and standard deviations shown on graphs.

\section{Results}

\subsection{Purification of D-PhgAT}

The results of plasmids construction and protein expression are reported previously (2). In purification phase, protein pellets from $25-45 \%$ fractional ammonium sulfate precipitation were loaded onto Phenyl Sepharose ${ }^{\circledR}$ FF column. Figure 1A shows the chromatogram and SDS-PAGE analysis of D-PhgAT peak eluted fractions of Phenyl Sepharose. Active fractions were loaded onto DEAE Sepharose ${ }^{\mathrm{TM}} \mathrm{FF}$ column. Figure 1B shows the chromatogram and SDSPAGE analysis of D-PhgAT peak eluted fractions of DEAE Sepharose. Table 1 shows the summary of this three-step purification strategy.

\subsection{Effect of Different Miscible Organic Solvents on} pH Values of D-PhgAT Reaction Buffer

Figure 2 shows spectrogram and maximum absorbance peaks $\left(\lambda_{\text {Max }}\right)$ of $50 \mathrm{mM} \mathrm{CAPSO} \mathrm{buffer} \mathrm{(various} \mathrm{pH}$ ) at 595 $\mathrm{nm}$ which used to plot reference curve and spectrograms of proportions of acetone, DMF, isopropanol in CAPSO buffer $\mathrm{pH}$ 9.5. Upon adding an organic solvent, the $\mathrm{pH}$ value of CAPSO buffer changed drastically. Figure 2A shows $\lambda_{\max }$ of $50 \mathrm{mM}$ CAPSO buffer with various $\mathrm{pH}$ at $594 \mathrm{~nm}$ and used to calculate pka values (equation 1). These pka values and $\lambda_{\max }$ at $594 \mathrm{~nm}$ upon adding miscible organic solvents to CAPSO buffer $\mathrm{pH} 9.5$ (Figs. 2B, 2C and 2D) where used to estimate $\mathrm{pH}$ shift $(\Delta \mathrm{pH})$ of CAPSO buffer. The buffer $\mathrm{pH}$ was reduced as 

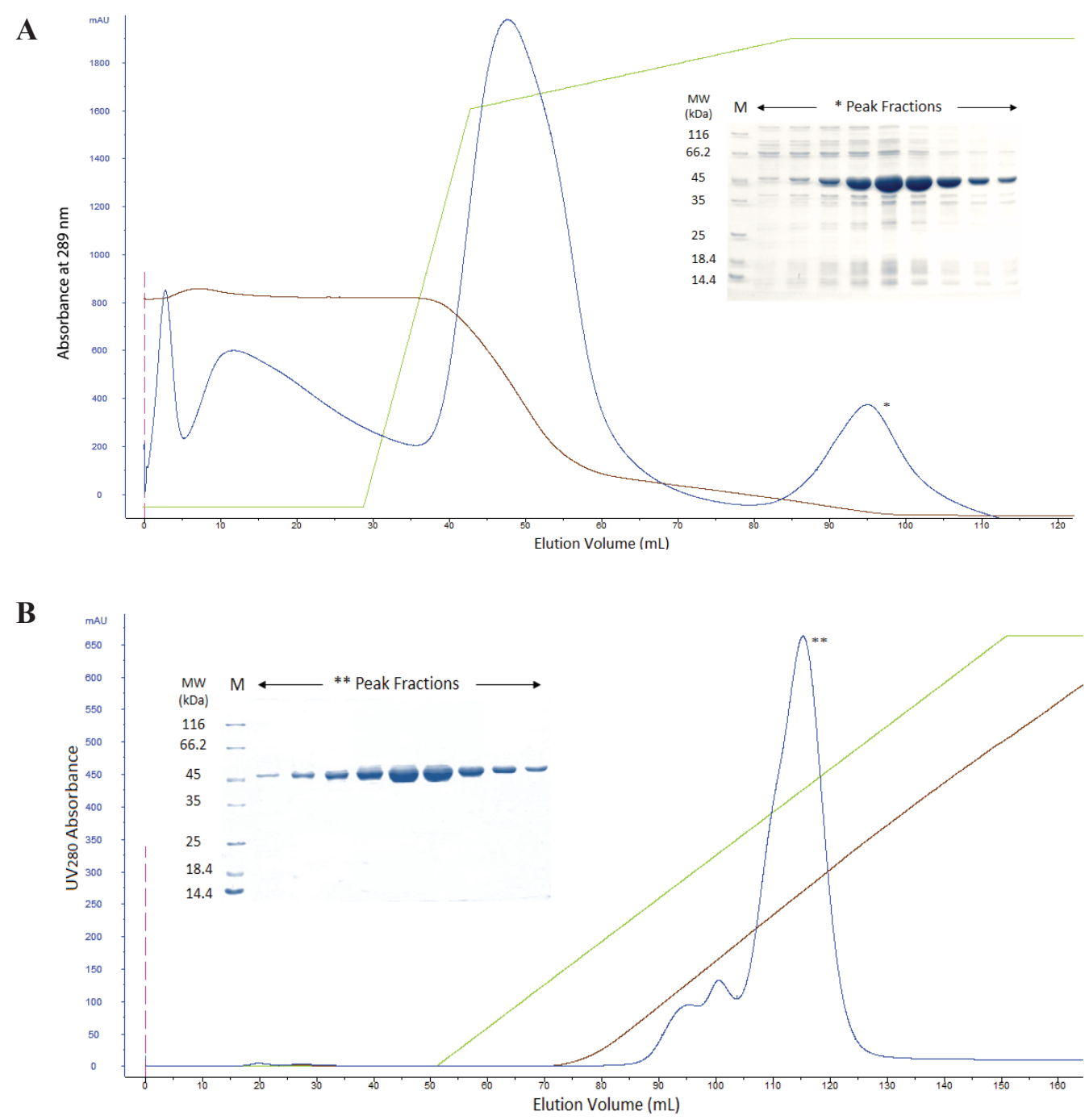

Figure 1. Purification chromatograms D-PhgAT. (A) The chromatogram of Phenyl Sepharose 6 FF hydrophobic interaction chromatography. Peak fractions $(*)$ containing D-PhgAT analyzed with SDSPAGE. (B) The chromatogram of DEAE Sepharose FF ion exchange chromatography. Peak fractions (**) containing D-PhgAT analyzed with SDS-PAGE. The pink line (injection into the column), the blue graph (UV280 absorbance graph), the green line (Concentration gradient of elution buffer) and the brown graph (Conductivity).

proportions of organic solvents increased. To minimize unfavorable $\mathrm{pH}$ change and effects on D-PhgAT performance, CAPSO buffer with various $\mathrm{pH}$ used to maintain $\mathrm{pH}$ at 9.5 .

\subsection{Effects of Various Fractions of Miscible Organic Solvents on D-PhgAT}

The D-PhgAT performance determined in reaction mixtures contained $0,10,20,30$ and $40 \%$ of miscible organic solvents (Fig. 3). The organic solvent concentrations, where $50 \%$ of enzyme activity $\left(C_{50}\right)$ retained are shown in Table 2. The performance of all D-PhgAT variants decreased as the concentration of solvents increased, especially in presence of DMF and acetone. No activity observed for methanol.

\subsection{D-PhgAT Performance and Absolute Organic Solvents}

D-PhgAT performance determined prior and after desiccation in TEMP buffer and in organic solvents at various temperatures (Fig. 4). After desiccation in TEMP buffer, absolute acetone and isopropanol and rehydration, residual activity of all D-PhgAT variants decreased in a temperature-dependent manner. The highest residual activity detected for ALAL-D-PhgAT at all temperatures. In case of DMF, the highest residual 
Table 1. Purification table of defferent variants of D-PhagAT.

\begin{tabular}{|c|c|c|c|c|c|c|}
\hline Purification steps & Protein variants & $\begin{array}{l}\text { Total protein } \\
\text { (mg) }\end{array}$ & Total activity (U) & $\begin{array}{l}\text { Specific activity } \\
\quad\left(\text { U.mg }^{-1}\right)\end{array}$ & Purification fold & $\begin{array}{c}\text { Yield } \\
(\%)\end{array}$ \\
\hline \multirow{4}{*}{$\begin{array}{c}\text { Clarified cell } \\
\text { lysate }\end{array}$} & WT-D-PhgAT & 92.56 & 474.20 & 5.12 & 1 & 100 \\
\hline & $\mathrm{A}_{1}-\mathrm{D}-\mathrm{PhgAT}$ & 89.30 & 446.50 & 5.00 & 1 & 100 \\
\hline & $\mathrm{A}_{2}-\mathrm{D}-\mathrm{PhgAT}$ & 91.20 & 460.56 & 5.05 & 1 & 100 \\
\hline & ALAL-D-PhgAT & 93.12 & 485.15 & 5.21 & 1 & 100 \\
\hline \multirow{4}{*}{$\underset{\text { precipitation }}{\left(\mathrm{NH}_{4}\right)_{2} \mathrm{SO}_{4}}$} & WT-D-PhgAT & 29.85 & 285.60 & 9.57 & 1.86 & 60.22 \\
\hline & $\mathrm{A}_{1}-\mathrm{D}-\mathrm{PhgAT}$ & 30.58 & 302.74 & 9.90 & 1.98 & 67.80 \\
\hline & $\mathrm{A}_{2}-\mathrm{D}-\mathrm{PhgAT}$ & 30.70 & 297.48 & 9.69 & 1.91 & 64.57 \\
\hline & ALAL-D-PhgAT & 32.33 & 321.68 & 9.95 & 1.90 & 66.30 \\
\hline \multirow{4}{*}{$\begin{array}{c}\text { Phenyl } \\
\text { Sepharose 6 FF } \\
\text { (HIC) }\end{array}$} & WT-D-PhgAT & 5.53 & 187.85 & 33.97 & 6.63 & 39.61 \\
\hline & $\mathrm{A}_{1}-\mathrm{D}-\mathrm{Phg} \mathrm{AT}$ & 5.56 & 198.15 & 35.64 & 7.12 & 44.37 \\
\hline & $\mathrm{A}_{2}-\mathrm{D}-\mathrm{PhgAT}$ & 5.59 & 191.73 & 34.30 & 6.79 & 41.62 \\
\hline & ALAL-D-PhgAT & 5.63 & 201.66 & 35.82 & 6.87 & 41.56 \\
\hline \multirow{4}{*}{$\begin{array}{c}\text { DEAE Sepharose } \\
\text { FF (IEX) }\end{array}$} & WT-D-PhgAT & 1.58 & 136.24 & 86.23 & 16.84 & 28.73 \\
\hline & $\mathrm{A}_{1}-\mathrm{D}-\mathrm{PhgAT}$ & 1.64 & 142.15 & 86.98 & 17.39 & 31.83 \\
\hline & $\mathrm{A}_{2}$-D-PhgAT & 1.61 & 155.70 & 86.71 & 17.17 & 33.80 \\
\hline & ALAL-D-PhgAT & 1.68 & 146.78 & 87.37 & 16.76 & 30.25 \\
\hline
\end{tabular}

The specific activity of enzyme variants in each step is divided by the specific activity of clarified cell lysate to calculate purification fold. The total activity of enzyme variants in each step is divided by the total activity of clarified cell lysate to calculate purification yield in percent.

$\mathbf{A}$

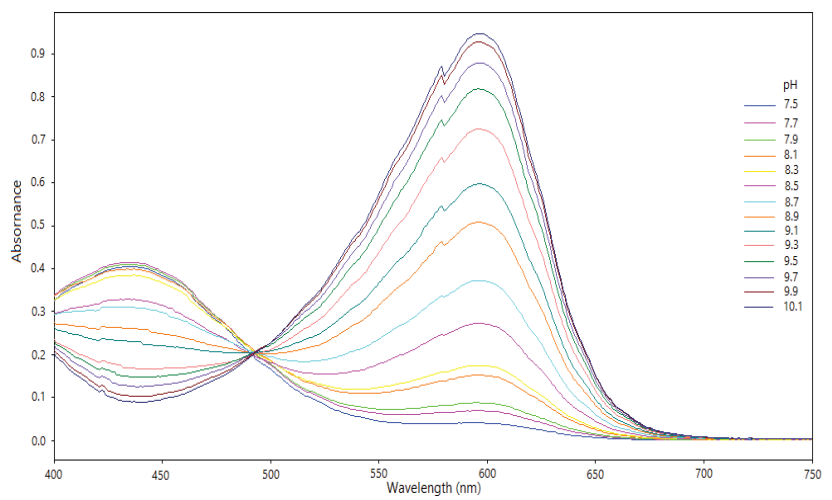

C

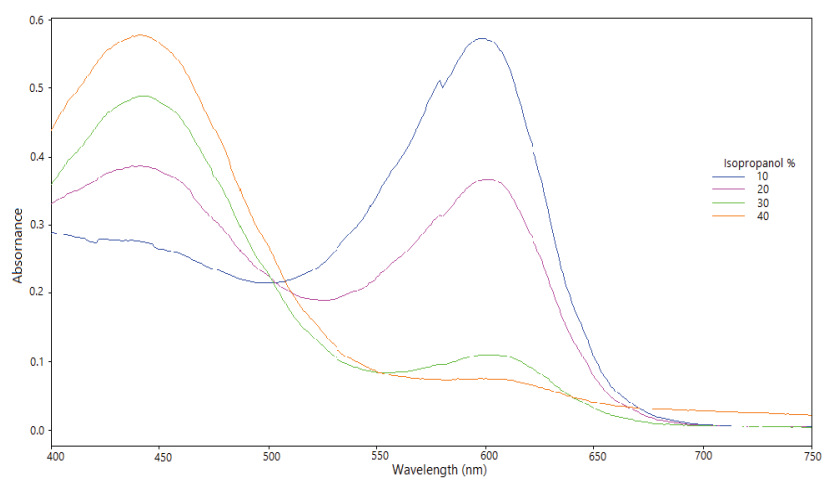

B

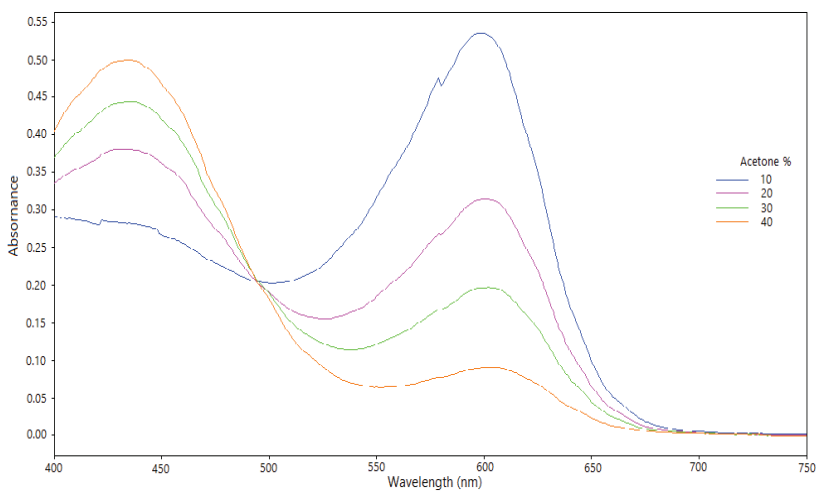

D

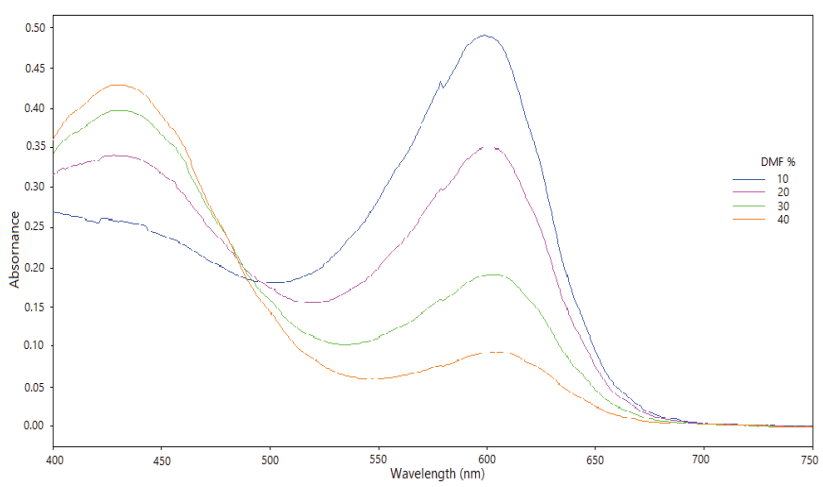

Figure 2. The spectrogram at $400 \mathrm{~nm}-750 \mathrm{~nm}$ of (A) $50 \mathrm{mM}$ CAPSO buffer + thymol blue with various $\mathrm{pH}$ values, and different fractions of acetone (B), isopropanol (C) and DMF (D), respectively, in $50 \mathrm{mM}$ CAPSO buffer $\mathrm{pH} 9.5+$ thymol blue. 

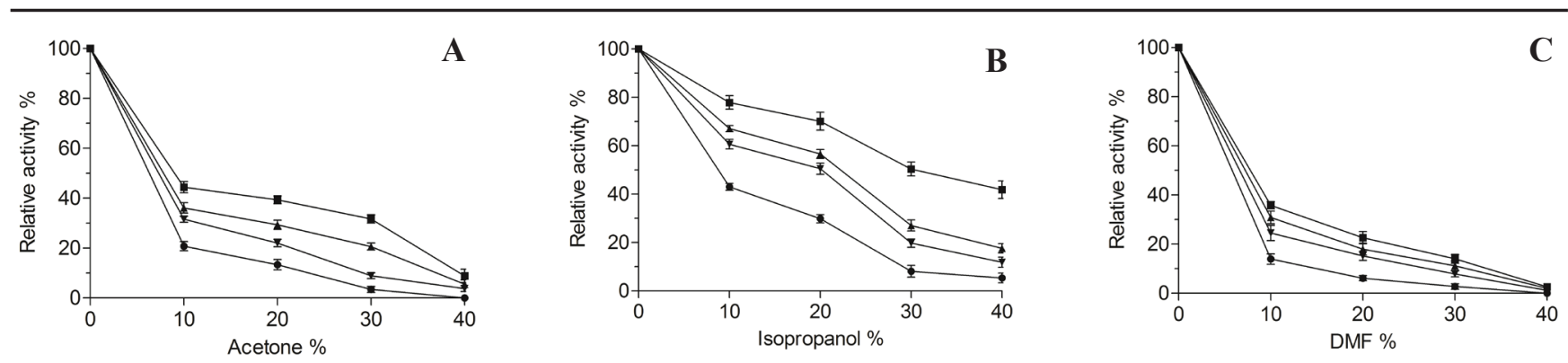

Figure 3. Shows effects of various fractions of $(\mathbf{A})$ acetone, $(\mathbf{B})$ isopropanol and $(\mathbf{C})$ DMF water-miscible organic binary solvents on of D-PhgAT variants. WT-D-PhgAT $(\bullet), \mathrm{A}_{1}$-D-PhgAT $(\boldsymbol{\Delta}), \mathrm{A}_{2}$-D-PhgAT $(\boldsymbol{\nabla})$ and ALAL-DPhgAT ( $\bullet$ ). Bars represent the standard deviation $(\mathrm{n}=3)$

activity observed at $40{ }^{\circ} \mathrm{C}$ for all variants while no activity observed at $60^{\circ} \mathrm{C}$.

\section{Discussion}

D-PhgAT Purification achieved in three steps. Firstly, at a specific concentration of ammonium sulfate, protein surficial charges are neutralized and the tendency of a protein to overcome aggregation is nullified. For D-PhgAT, 25-45\% saturation was executed with 60-70\% yield and 1.8-1.9fold purification. Secondly, protein

A

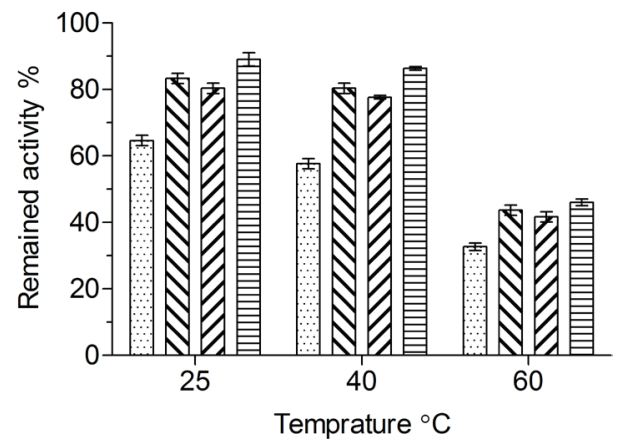

C

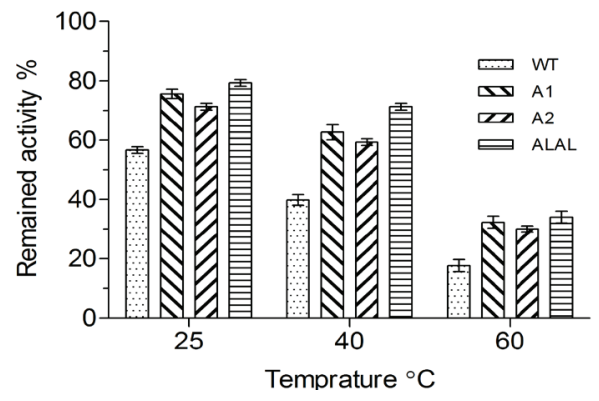

pellets from fractional precipitation dissolved in TEMP buffer containing $1 \mathrm{M}$ ammonium sulfate and applied on the Phenyl Sepharose. Pre-equilibration with $1 \mathrm{M}$ ammonium sulfate eliminates free water molecules in microenvironments around hydrophobic phenyl ligands that is essential for binding of hydrophobic proteins via their surficial hydrophobic patches. After elution of bound proteins by descending gradient of ammonium sulfate, 39-44 \% yield and 6-7 fold purification achieved. Lastly, active fractions desalted completely

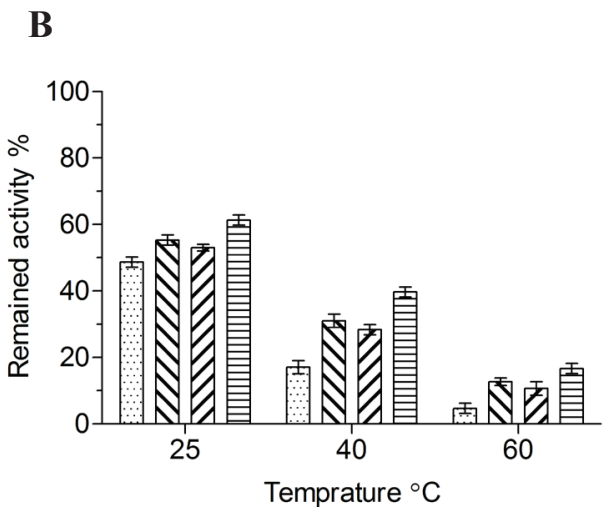

D

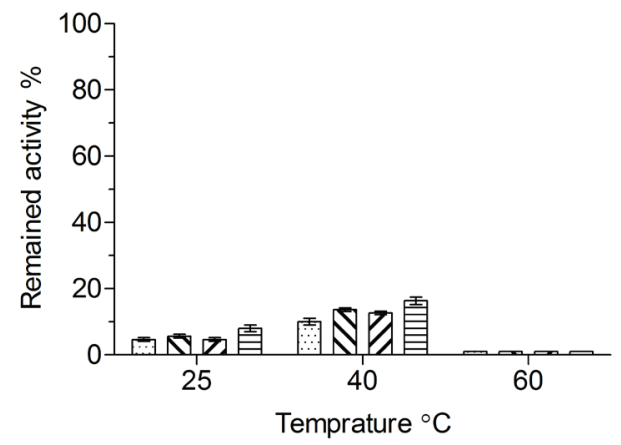

Figure 4. Remained activity of D-PhgAT variants at (A) TEMP buffer $\mathrm{pH} 7.6$ as control and absolute miscible organic solvents (B) acetone, $(\mathbf{C})$ isopropanol and (D) DMF; after $1 \mathrm{~h}$ incubation at different temperatures $\left(25,40\right.$ and $\left.60{ }^{\circ} \mathrm{C}\right)$. Bars represent the standard deviation $(n=3)$ 
Table 2. $C_{50}$ values of D-PhgAT variants in different organic solvents

\begin{tabular}{lccc}
\hline Protein variants & DMF & $\begin{array}{c}\boldsymbol{C}_{\mathbf{5 0}}(\mathbf{\%} \mathbf{~ V / V}) \\
\text { Acetone }\end{array}$ & Isopropanol \\
\hline WT-D-PhgAT & $5.82 \pm 0.86$ & $6.27 \pm 0.72$ & $8.70 \pm 0.47$ \\
A 1 -D-PhgAT & $7.22 \pm 0.35$ & $7.80 \pm 0.49$ & $22.30 \pm 1.52$ \\
A - D-PhgAT & $6.60 \pm 0.48$ & $7.20 \pm 0.53$ & $20.10 \pm 2.30$ \\
ALAL-D-PhgAT & $7.80 \pm 0.62$ & $9.00 \pm 0.97$ & $30.20 \pm 2.84$ \\
\hline
\end{tabular}

Different variants of D-PhgAT examined against fractions of the selected organic solvents in reaction media. The organic solvent where $50 \%$ of enzyme activity remained $\left(\mathrm{C}_{50}\right)$ was used to compare the stability of variants in presence miscible organic solvents. The experiments done in triplicated (mean $\pm \mathrm{SD}, \mathrm{n}=3$ )

and injected into DEAE Sepharose which was preequilibrated with TEMP buffer. In contrast with HIC; the IEX column separates proteins based on charge differences and isoelectric $\mathrm{pH}(\mathrm{pI})$. Different variants of D-PhgAT have $\mathrm{pI}$ range from 5.28 to $6.2(1,2)$, thus in TEMP buffer, D-PhgAT will be negatively charged and binds to positively charged diethylaminoethyl ligands. Elution of bound proteins in this step happened with ascending gradient of $\mathrm{NaCl}$, in which $\mathrm{Cl}^{-}$substituted with D-PhgAT. In this step 28-30\% yield and 16-17 fold purification achieved.

In aqueous solutions, $\mathrm{pH}$ value largely influences solubility, performance and stability of enzymes (18, 22). Addition of organic solvents into a buffer shifts $\mathrm{pH}$ value drastically (23) with plausible indecent effects on protein. Aiming to verify the effects of organic solvents on D-PhgAT, interrogation of their effects on $\mathrm{pH}$ value of CAPSO buffer $\mathrm{pH} 9.5$ is irrevocable. Thymol blue with the second transition, yellow-blue at $\mathrm{pH}$ 8.0-9.6 and average pka 8.9 used as an indicator. Owing to pka shift in different $\mathrm{pH}$, pka of each was calculated. Upon adding solvents to an aqueous buffered solution, the pka of the acid participant and the solvents autoprotolysis constant change and as a result, $\mathrm{pH}$ jumps $(23,24)$. To maintain $\mathrm{pH}$ at 9.5 and minimize unfavorable $\mathrm{pH}$ change on D-PhgAT performance, CAPSO buffer with various $\mathrm{pH}$ used.

Upon increasing proportion of organic solvents up to $40 \%$, the performance of D-PhgAT variants diminished, which at least partly could be due to the denaturation capacity of solvents $(21,25)$. The $\log p$ value (octanol/ water partition coefficient) is -1.01 for DMF and -0.24 for acetone (26). Both have low hydrophobicity, thus are highly potent to strip water molecules off the hydration shell at the expense of proteins flexibility (27) therefore promote denaturation and inactivation of D-PhgAT.

The fusion of halophilic peptides provides eminent numbers of negatively charged residues which serve as extra sites for water molecules binding, therefore maintaining protein hydration shell and partial activity preservation. Methanol has $\log p$ value -0.81 (26) seems to strip more water molecules off the protein hydration shell at expense of flexibility. Moreover, structural studies have shown that aqueous solution of methanol stabilizes $\alpha$-helixes and simultaneously denatures other structures or accumulates on protein surface (28). All these reasons participate to nullify D-PhgAT performance in methanol solutions. Despite large performance decrease in DMF, acetone and methanol solutions, D-PhgAT showed higher performance in isopropanol $(\log p$ 0.05) solution (26) which indicate relatively higher hydrophobicity of isopropanol compared with other used solvents. This isopropanol characteristic results in stripping fewer water molecules off the hydration shell of proteins and thereby results in more flexibility and less denaturation. In all cases, halophilic fused variants manifest higher $C_{50}$ value compared with wild-type (Table 2), where the highest $C_{50}$ observed for ALAL-D-PhgAT in isopropanol solutions $\left(C_{50}: 30.20 \pm 2.84(\% \mathrm{~V} / \mathrm{V})\right)$.

In presence of absolute organic solvents, the interval dehydration and raised temperature increased denaturation propensity. Owing to decreased water as a molecular lubricant (29) and insufficient flexibility for denaturation (30) protein rigidity increased, so protection against temperature stress developed. Halophilic proteins, owing to their charged residues, manifest interesting interactions with salts in aqueous or organic solutions which maintain their active structures in dry conditions (31). Therefore, it is feasible to assume fusion of halophilic peptides preserves the active structure of D-PhgAT in dehydrated conditions and elevates the thermostability. Compared with aqueous solutions, thermostability of D-PhgAT variants in presence of absolute organic solvents increased as the $\log p$ of the organic solvents increased. DMF (log $p$ : -1.01) has highest adverse effect compared with acetone $(\log p:-0.24)$ and isopropanol $(\log p: 0.05)$. The 
rigidity and eliminated water participation in hydrogen bonds after dehydration, reduced dielectric constant and increased strong intra-protein interactions, reduce remained activity in such absolute non-aqueous media. Surprisingly, in case of DMF, the residual activity at $40{ }^{\circ} \mathrm{C}$ of all D-PhgAT variants was higher than 25 ${ }^{\circ} \mathrm{C}$ and was zero at $60{ }^{\circ} \mathrm{C}$. This unusual behavior of D-PhgAT in presence of absolute DMF is yet to be fully understood but might be due to the nature and position of amino acid residues in $\mathrm{A}_{2}$ alpha helix, yet it cannot explain the higher remained activity of WT-D-PhgAT at $40{ }^{\circ} \mathrm{C}$ than $25^{\circ} \mathrm{C}$.

Removing solvents and then rehydration elevates flexibility and partially restores D-PhgAT performance. Dehydration-rehydration cycles also lead to irreversible protein damages $(32,33)$ and diminish performance (which is highly $\mathrm{pH}$ dependent) as an outcome of side chains ionization and salt bridge alternation. Some organic solvents e.g., glycerol and ethylene glycol mimic the water effect owing to multiple hydrogen bonds formation. Crown ethers can bind to cationic groups e.g., amine groups and stabilize molecular interactions and protein structure and cyclodextrins by the formation of stable supramolecular complexes and clasp hydrophobic amino acid residues in their inner cavities (34).

Our results, hereby, confirmed that practiced halophilic peptide fusion can increase thermostability of a mesophilic protein, both in aqueous and nonaqueous media.

\section{Conclusion}

Despite many benefits of utilizing enzymes in biotechnological processing, they might largely suffer from denaturation and performance reduction. Additionally, insolubility of substrates or products and occasional microbial contamination are problematic. A suggested strategy to partially eliminate these drawbacks is applying miscible organic solvents in enzyme media. Nevertheless, miscible organic solvents might have detrimental effects. Extremophiles, particularly halophiles, have extraordinary properties to withstand unsavory habitats, making them invaluable for industrial applications. In this study, for the first time, we practiced the effects of fusion of two alpha helixes and loops between them from a halophilic enzyme at N-terminus domain of mesophilic D-PhgAT, as an industrial model enzyme in presence of miscible organic solvents at various temperatures. Our results suggest that applying this new technique could be an invaluable pragmatic strategy for engineering durable enzymes for precluding industrial applications.

\section{Acknowledgment}

This research was funded by the Thailand Research Fund, Grant No. RSA4780014 and by the Scholarships for International Ph.D. Students, Faculty of Graduate Studies, Mahidol University, Bangkok, Thailand. We gratefully thank Prof. Vithaya Meevootisom and Mrs. Duangnate Isarangkul, Department of Microbiology, Faculty of Science, Mahidol University, Bangkok, Thailand.

\section{References}

1. Wiyakrutta S, Meevootisom V. A stereo-inverting D-phenylglycine aminotransferase from Pseudomonas stutzeri ST-201: purification, characterization and application for D-phenylglycine synthesis. J Biotechnol. 1997;55(3):193-203. doi: 10.1016/S0168-1656(97)00075-8

2. Javid H, Jomrit J, Chantarasiri A, Isarangkul D, Meevootisom V, Wiyakrutta S. Effects of halophilic peptide fusion on solubility, stability, and catalytic performance of D-phenylglycine aminotransferase. J Microbiol Biotechnol. 2014;24(5):597-604. doi: $10.4014 / \mathrm{jmb} .1312 .12040$

3. Iyer PV, Ananthanarayan L. Enzyme stability and stabilizationAqueous and non-aqueous environment. Proc Biochem. 2008;43(10):1019-1032. doi : 10.1016/j.procbio.2008.06.004

4. Shultz MJ. Liquid interfaces in chemical, biological, and pharmaceutical applications. $J$ Am Chem Soc. 2001;123(41):10143-10143. doi: 10.1021/ja015249a

5. Klibanov AM. Improving enzymes by using them in organic solvents. Nature. 2001;409(6817):241-246. doi: $10.1038 / 35051719$

6. Zaks A, Klibanov AM. Enzymatic catalysis in nonaqueous solvents. J Biol Chem. 1988;263(7):3194-3201.

7. Kieboom APG. Enzymes that do not work in organic solvents. In: Abramowicz DA, editor. Biocatalysis. Dordrecht: Springer Netherlands; 1990;p:357-364. doi: 10.1007/978-94-010-91244_17

8. Raddadi N, Cherif A, Daffonchio D, Neifar M, Fava F. Biotechnological applications of extremophiles, extremozymes and extremolytes. ApplMicrobiol Biotechnol.2015;99(19):79077913. doi: 10.1007/s00253-015-6874-9

9. Adrio J-L, Demain AL. Recombinant organisms for production of industrial products. Bioeng Bugs. 2010;1(2):116-131. doi: 10.4161/bbug.1.2.10484

10. Sugathan S, Pradeep NS, Abdulhameed S. Bioresources and Bioprocess in Biotechnology. Singapore: Springer Singapore; 2017;p:151-68. doi: 10.1007/978-981-10-4284-3

11. DeSantis G, Jones JB. Chemical modification of enzymes for enhanced functionality. Curr Opin Biotechnol. 1999;10(4):324330. doi: 10.1016/S0958-1669(99)80059-7

12. Nwagu TN, Okolo B, Aoyagi H, Yoshida S. Chemical modification with phthalic anhydride and chitosan: Viable options for the stabilization of raw starch digesting amylase from Aspergillus carbonarius. Int J Biol Macromol. 2017;99:641647. doi: 10.1016/j.ijbiomac.2017.03.022

13. D'Amico S, Marx JC, Gerday C, Feller G. Activity-stability relationships in extremophilic enzymes. $J$ Biol Chem. 2003;278(10):7891-7896. doi: 10.1074/jbc.M212508200

14. Kunte HJ, TrüperHG, Stan-LotterH.Halophilic microorganisms. Astrobiology In: The quest for the conditions of life. Berlin, 
Heidelberg. Springer Berlin Heidelberg; 2002;p:185-200. doi: 10.1007/978-3-642-59381-9

15. Jaakkola ST, Zerulla K, Guo Q, Liu Y, Ma H, Yang C, et al. Halophilic archaea cultivated from surface sterilized middle-late eocene rock salt are polyploid. PLoS One. 2014;9(10):e110533. doi: 10.1371/journal.pone.0110533

16. Karan R, Capes MD, DasSarma S. Function and biotechnology of extremophilic enzymes in low water activity. Aquat Biosyst. 2012;8(1):4. doi: 10.1186/2046-9063-8-4

17. Gupta S, Sharma P, Dev K, Sourirajan A. Halophilic bacteria of lunsu produce an array of industrially important enzymes with salt tolerant activity. Biochem Res Int. 2016;2016:10. doi: $10.1155 / 2016 / 9237418$

18. Shubhada S, Sundaram PV. The role of $\mathrm{pH}$ change caused by the addition of water-miscible organic solvents in the destabilization of an enzyme. Enz Micro Technol. 1995;17(4):330-335. doi: 10.1016/0141-0229(94)00028-X

19. L. E. Vidal Salgado CV-H. Spectrophotometric determination of the pka, isosbestic point and equation of absorbance vs. ph for a universal ph indicator. American J Anal Chem. 2014;5(17):1290-1301. doi: 10.4236/ajac.2014.517135

20. Patterson GS. A simplified method for finding the pka of an acid-base indicator by spectrophotometry. J Chem Ed . 1999;76(3):395.

21. Miroliaei M, Nemat-Gorgani M. Effect of organic solvents on stability and activity of two related alcohol dehydrogenases: a comparative study. Int J Biochem Cell Biol. 2002;34(2):169175. doi: 10.1016/S1357-2725(01)00109-1

22. Klibanov AM. Why are enzymes less active in organic solvents than in water? Trends Biotechnol. 1997;15. doi: 10.1016/S01677799(97)01013-5

23. Subirats X, Rosés M, Bosch E. On the effect of organic solvent composition on the ph of buffered HPLC mobile phases and the pk a of analytes-a review. Sep Pur Rev. 2007;36(3):231-255. doi: 10.1080/15422110701539129

24. Kiliç E, Aslan N. Determination of autoprotolysis constants of water-organic solvent mixtures by potentiometry. Microchimica Acta. 2005;151(1):89-92. doi: 10.1007/s00604-005-0380-1

25. Khmelnitsky YL, Mozhaev VV, Belova AB, Sergeeva MV, Martinek K. Denaturation capacity: a new quantitative criterion for selection of organic solvents as reaction media in biocatalysis. Eur J Biochem. 1991;198(1):31-41. doi: 10.1111/ j.1432-1033.1991.tb15983.x

26. Sangster J. Octanol-water partition coefficients of simple organic compounds. J Phys Chem Ref Data. 1989;18(3):11111229. doi: $10.1063 / 1.555833$

27. Hartsough DS, Merz KM. Protein flexibility in aqueous and nonaqueous solutions. $J$ American Chem Soci. 1992;114(26):10113-10116. doi: 10.1021/ja00052a004

28. Hwang S, Shao Q, Williams H, Hilty C, Gao YQ. Methanol strengthens hydrogen bonds and weakens hydrophobic interactions in proteins - a combined molecular dynamics and NMR study. J Phys Chem B. 2011;115(20):6653-6660. doi: $10.1021 / j p 111448 \mathrm{a}$

29. Stepankova V, Bidmanova S, Koudelakova T, Prokop Z, Chaloupkova R, Damborsky J. Strategies for stabilization of enzymes in organic solvents. ACS Catal. 2013;3(12):28232836. doi: $10.1021 / \operatorname{cs} 400684 x$

30. Mukherjee J, Gupta MN. Increasing importance of protein flexibility in designing biocatalytic processes. Biotechnol Rep. 2015;6:119-123. doi: 10.1016/j.btre.2015.04.001

31. Patel S, Saraf M. Perspectives and application of halophilic enzymes. In: Halophiles: Biodiversity and Sustainable Exploitation, edited by Maheshwari DK, Saraf M, Springer International Publishing; 2015;p:403-419. doi: 10.1007/978-3319-14595-2

32. Qvist J, Ortega G, Tadeo X, Millet O, Halle B. Hydration dynamics of a halophilic protein in folded and unfolded states. J Phys Chem B. 2012;116(10):3436-3444. doi: 10.1021/ jp3000569

33. Noinville S, Revault M, Quiquampoix H, Baron MH. Structural effects of drying and rehydration for enzymes in soils: a kinetics-FTIR analysis of alpha-chymotrypsin adsorbed on montmorillonite. J Colloid Interface Sci. 2004;273(2):414-425. doi: 10.1016/j.jcis.2004.01.067

34. Lee C-C, Maestre-Reyna M, Hsu K-C, Wang H-C, Liu C-I, Jeng $\mathrm{W}-\mathrm{Y}$, et al. Crowning proteins: modulating the protein surface properties using crown ethers. Angew Chem Int Ed Engl. 2014;53(48):13054-13058. doi: 10.1002/anie.201405664 